\title{
ANALISIS VARIANSI PADA RANCANGAN BUJUR SANGKAR YOUDEN DENGAN DUA DATA HILANG
}

\author{
Amalina Sari Dewi ${ }^{1}$, Tatik Widiharih ${ }^{2}$, Rita Rahmawati ${ }^{3}$ \\ ${ }^{1,2,3}$ Departemen Statistika FSM Universitas Diponegoro \\ widiharih@gmail.com
}

\begin{abstract}
Youden Square Design (YSD) is an incomplete latin square design with at least one row/column which can't run in an experiment. In this research we took 5x4 YSD (one column is not runned in an experiment). This design has a balance characteristic from a balanced incomplete block design where all treatments appears with the same number in each row. Missing data can occur in YSD. In this discussion, YSD with two missing data was used. Missing data is estimated by an iterative method then we arrange analysis of variance and LSD test. Analysis of variance with two missing data in YSD is calculated by adjusting the treatment sum of squares with it's bias value and the total degrees of freedom and error degrees of freedom are substracted by two. LSD test is carried out if the treatment has a significant effect to the response. To clarify the discussion in YSD, example of application in the field of industry is given by observing the effect of the assembly method to the length of assembly time of X component. The assembly method has an effect to the length of assembly time of $\mathrm{X}$ component and if the missing data are $x_{531}$ and $x_{445}$ so the suggested assembly method is E method because it has the fastest average assembly time.
\end{abstract}

Keywords: YSD, Missing Data, Analysis of Variance, LSD Test

\section{PENDAHULUAN}

Menurut Montgomery (2009), rancangan percobaan merupakan suatu uji atau serangkaian uji dengan maksud untuk mengamati dan mengidentifikasi perubahanperubahan pada variabel output (respon) yang disebabkan oleh perubahan-perubahan yang dilakukan pada variabel input (faktor) dari suatu proses. Rancangan yang paling sederhana diantara rancangan-rancangan percobaan yang lain yaitu Rancangan Acak Lengkap (RAL). RAL digunakan apabila satuan percobaan yang digunakan relatif homogen. Namun apabila kondisi ini tidak dipenuhi maka perlu dilakukan upaya pengendalian lokal berupa pengelompokan satuan percobaan ke dalam kelompok-kelompok yang relatif homogen. Rancangan Acak Kelompok (RAK) dapat digunakan dengan mengelompokkan satuan percobaan menurut satu arah. Apabila dilakukan pengelompokan dua arah (baris dan kolom) maka Rancangan Bujur Sangkar Latin (RBSL) dapat digunakan. Pada RBSL, setiap perlakuan hanya dicobakan satu kali dalam setiap baris dan kolom sehingga jumlah perlakuan harus sama dengan jumlah baris dan kolom. Akan tetapi apabila banyaknya kolom atau baris tidak sama dengan banyaknya perlakuan yang diamati maka RBSL tidak dapat diterapkan. Rancangan yang tepat untuk kasus tersebut yaitu Rancangan Bujur Sangkar Youden (RBSY).

Menurut Gaspersz (1991), Rancangan Bujur Sangkar Youden (RBSY) merupakan rancangan bujur sangkar latin tak lengkap, dimana banyaknya kolom tidak sama dengan banyaknya baris dan perlakuan dalam suatu percobaan. Selain itu, RBSY memiliki sifat keseimbangan dari Rancangan Acak Kelompok Tak Lengkap Seimbang (RAKTLS) yaitu 
semua perlakuan dicobakan dalam jumlah yang sama di setiap baris atau kolom. Dengan demikian RBSY merupakan kombinasi dari RBSL dan RAKTLS (Oehlert, 2010). Setiap rancangan percobaan sangat mungkin mengalami masalah data hilang, termasuk juga dalam RBSY. Dalam tulisan ini, dua buah data hilang diestimasi terlebih dahulu sehingga nantinya dapat dilakukan analisis variansi dan uji lanjutnya.

\section{TINJAUAN PUSTAKA}

\subsection{Rancangan Percobaan}

Percobaan adalah suatu usaha yang direncanakan dengan baik untuk menemukan fakta-fakta baru atau untuk memperkuat dan bahkan menolak hasil-hasil percobaan yang sudah ada sebelumnya. Rancangan percobaan ialah seperangkat aturan yang dipakai untuk mengambil contoh dari populasi yang diteliti, supaya diperoleh penduga parameter yang tepat dan teliti dengan biaya, waktu serta tenaga yang terbatas (Kusriningrum, 2008). Menurut Suwanda (2011), tujuan dari rancangan percobaan yaitu untuk memperoleh atau mengumpulkan informasi sebanyak-banyaknya yang diperlukan dan berguna dalam melakukan penyelidikan persoalan yang akan dibahas.

Dalam rancangan percobaan, satuan-satuan percobaan dapat dikelompokan berdasarkan baris dan kolom, salah satunya dengan Rancangan Bujur Sangkar Latin (RBSL) (Montgomery, 2009). Setiap perlakuan hanya dicobakan satu kali dalam setiap baris dan kolom. Jumlah perlakuan dalam rancangan ini harus sama dengan jumlah baris dan kolom. Secara umum, model linier untuk RBSL dengan $r$ perlakuan adalah (Gaspersz, 1991):

$$
\begin{gathered}
y_{i j(k)}=\mu+\alpha_{i}+\beta_{j}+\tau_{(k)}+\varepsilon_{i j(k)} \\
i, j, k=1,2, \ldots, r
\end{gathered}
$$

Bila digunakan model tetap, asumsinya sebagai berikut:

1. $\sum \alpha_{i}=0, \sum \beta_{j}=0$ dan $\sum \tau_{(k)}=0$

2. $\varepsilon_{i j(k)} \sim \operatorname{NID}\left(0, \sigma^{2}\right)$

Perlakuan-perlakuan yang dicobakan dalam suatu rancangan terkadang tidak semuanya muncul bersamaan pada kelompok yang sama. Rancangan yang dapat digunakan untuk kasus tersebut yaitu Rancangan Acak Kelompok Tak Lengkap Seimbang (RAKTLS). Rancangan ini merupakan rancangan dimana perlakuan yang digunakan dalam masingmasing kelompok dipilih dalam suatu cara yang seimbang sehingga pasangan-pasangan perlakuan muncul dalam jumlah yang sama untuk setiap kelompok sebagaimana pasanganpasangan perlakuan yang lain (Montgomery, 2009). Banyaknya tiap pasang perlakuan yang muncul dalam kelompok yang sama $(\lambda)$ adalah

$\lambda=\frac{r(k-1)}{a-1}$, dengan

$r$ : banyaknya ulangan dari setiap perlakuan

$k:$ ukuran kelompok

$a$ : banyaknya perlakuan

Secara umum, model linier untuk RAKTLS dengan $a$ perlakuan dan $b$ kelompok adalah (Gaspersz, 1991):

$$
\begin{gathered}
y_{i j}=\mu+\tau_{i}+\beta_{j}+\varepsilon_{i j} \\
i=1,2, \ldots, a ; j=1,2, \ldots, b
\end{gathered}
$$

Bila digunakan model tetap, asumsinya sebagai berikut:

1. $\sum \tau_{i}=0$ dan $\sum \beta_{j}=0$

2. $\varepsilon_{i j} \sim \operatorname{NID}\left(0, \sigma^{2}\right)$

\subsection{Rancangan Bujur Sangkar Youden}


Rancangan Bujur Sangkar Youden (RBSY) merupakan rancangan bujur sangkar latin tak lengkap, dimana banyaknya kolom tidak sama dengan banyaknya baris dan perlakuan dalam suatu percobaan (Gaspersz, 1991). Selain itu, RBSY memiliki sifat keseimbangan dari Rancangan Acak Kelompok Tak Lengkap Seimbang (RAKTLS) yaitu semua perlakuan dicobakan dalam jumlah yang sama di setiap baris atau kolom. Dengan demikian RBSY merupakan kombinasi dari RBSL dan RAKTLS (Oehlert, 2010). Apabila jumlah baris sama dengan jumlah perlakuan, maka model linier untuk rancangan bujur sangkar Youden dengan $a$ baris, $b$ kolom dan $a$ perlakuan adalah (Gaspersz, 1991):

$i=1,2, \ldots, a$

$$
y_{i j(k)}=\mu+\alpha_{i}+\beta_{j}+\tau_{(k)}+\varepsilon_{i j(k)}
$$

$j=1,2, \ldots, b$; dimana $b=a-n$ dan $n$ yaitu jumlah kolom yang hilang

$k=1,2, \ldots, a$

dengan:

$y_{i j(k)}=$ pengamatan pada baris ke- $i$, kolom ke- $j$ dan perlakuan ke- $k$

$\mu \quad=$ rataan umum

$\alpha_{i} \quad=$ pengaruh baris ke $-i$

$\beta_{j} \quad=$ pengaruh kolom ke- $j$

$\tau_{(k)}=$ pengaruh perlakuan ke- $k$

$\varepsilon_{i j(k)}=$ komponen galat

Bila digunakan model tetap, asumsinya sebagai berikut:

1. $\sum \alpha_{i}=0, \sum \beta_{j}=0$ dan $\sum \tau_{(k)}=0$

2. $\varepsilon_{i j(k)} \sim \operatorname{NID}\left(0, \sigma^{2}\right)$

Hipotesis pada RBSY untuk menguji pengaruh perlakuannya adalah:

$\mathrm{H}_{0}: \tau_{1}=\tau_{2}=\cdots=\tau_{a}=0$ (tidak ada pengaruh perlakuan terhadap respon yang diamati)

$\mathrm{H}_{1}$ : paling sedikit ada satu $\mathrm{k}$ dengan $\tau_{k} \neq 0, k=1,2, \ldots, a$ (ada pengaruh perlakuan terhadap respon yang diamati)

\subsubsection{Analisis Variansi untuk Rancangan Bujur Sangkar Youden}

Perhitungan-perhitungan untuk menyusun tabel ANOVA sebagai berikut:

$$
\begin{aligned}
& \mathrm{JKT}=\sum_{i=1}^{a} \sum_{j=1}^{b} \sum_{k=1}^{a} y_{i j k}^{2}-\frac{y_{\ldots}^{2}}{N} \\
& \mathrm{JKB}=\frac{1}{b} \sum_{i=1}^{a} y_{i . .}^{2}-\frac{y_{\ldots}^{2}}{N} \\
& \mathrm{JKK}=\frac{1}{a} \sum_{j=1}^{b} y_{. j .}^{2}-\frac{y_{\ldots .}^{2}}{N} \\
& \mathrm{JKP}_{(\text {disesuaikan })}=\frac{b}{\lambda a} \sum_{k=1}^{a} Q_{k}^{2} \\
& \mathrm{JKG}=\mathrm{JKT}-\mathrm{JKB}-\mathrm{JKK}_{-} \mathrm{JKP}_{(\text {disesuaikan })} \\
& \mathrm{KTB}=\frac{\mathrm{JKB}}{a-1} \\
& \mathrm{KTK}=\frac{\mathrm{JKK}}{b-1}
\end{aligned}
$$


$\mathrm{KTP}_{(\text {disesuaikan })}=\frac{\mathrm{JKP}_{(\text {disesuaikan })}}{a-1}$

$\mathrm{KTG}=\frac{\mathrm{JKG}}{(a-1)(b-2)}$

Tabel analisis variansinya disusun sebagai berikut:

\begin{tabular}{cccccc}
\hline $\begin{array}{c}\text { Sumber } \\
\text { Variansi }\end{array}$ & Derajat Bebas & $\begin{array}{c}\text { Jumlah } \\
\text { Kuadrat }\end{array}$ & $\begin{array}{c}\text { Kuadrat } \\
\text { Tengah }\end{array}$ & F hitung & $\mathrm{F}_{\text {tabel }}$ \\
\hline $\begin{array}{c}\text { Perlakuan } \\
\text { (disesuaikan) }\end{array}$ & $a-1$ & $\mathrm{JKP}_{\text {(disesuaikan) }}$ & $\mathrm{KTP}_{\text {(disesuaikan) }}$ & $\mathrm{KTP}_{(\text {disesuaikan) }} \mathrm{F}_{(a-1) ;(a-1)(b-2)}(\alpha)$ \\
\hline Baris & $a-1$ & $\mathrm{JKB}$ & $\mathrm{KTB}$ & \\
\hline Kolom & $b-1$ & JKK & KTK & \\
\hline Galat & $(a-1)(b-2)$ & JKG & KTG & \\
\hline Total & $a b-1$ & JKT & & \\
\hline dengan kriteria uji: tolak $\mathrm{H}_{0}$ jika $\mathrm{F}_{\text {hitung }}>\mathrm{F}_{\text {tabel }}$
\end{tabular}

\subsubsection{Uji Lanjut untuk Rancangan Bujur Sangkar Youden}

Dalam uji LSD, langkah-langkah pengujiannya sebagai berikut:

1. Mengurutkan rata-rata perlakuan dari yang terkecil sampai yang terbesar.

2. Menghitung standar error dari perlakuan ke-i dan perlakuan ke-j yang telah disesuaikan:

3. Menghitung LSD

$$
S_{\bar{y}_{i .}-\bar{y}_{j .}}=\sqrt{\frac{2(\mathrm{KTG})}{b} \frac{b(a-1)}{a(b-1)}}
$$

$\mathrm{LSD}=t_{\frac{\alpha}{2} ; d b . g} \times S_{\bar{y}_{i}-\bar{y}_{j} .}$

dimana $\frac{t_{\overline{2}}}{2}$;b.g merupakan nilai pada tabel distribusi t dengan tingkat signifikansi $\alpha$ dan derajat bebas galat (db.g).

4. Jika $\left|\bar{y}_{i .}-\bar{y}_{j .}\right|>$ LSD maka pasangan perlakuan tersebut berbeda signifikan.

\subsubsection{Uji Asumsi}

Asumsi-asumsi yang mendasari analisis variansi yang perlu diperhatikan agar pengujian menjadi sahih adalah galat percobaan menyebar normal (asumsi normalitas residual) serta galat percobaan mempunyai galat yang homogen (asumsi homogenitas residual).

\section{a. Asumsi Normalitas}

Menurut Daniel (1989), uji normalitas secara formal dapat dilakukan dengan uji

Kolmogorov-Smirnov. Hipotesisnya sebagai berikut:

$\mathrm{H}_{0}$ : data residual menyebar normal

$\mathrm{H}_{1}$ : data residual tidak menyebar normal

Statistik Uji: $\mathrm{D}=\sup \left|\mathrm{S}(\mathrm{x})-\mathrm{F}_{0}(\mathrm{x})\right|$

dengan:

$\mathrm{S}(\mathrm{x})=$ Proporsi nilai-nilai pengamatan dalam sampel yang kurang dari atau sama dengan $\mathrm{x}$ $\mathrm{F}_{0}(\mathrm{x})=$ Fungsi sebaran normal kumulatif

Keputusan:

Jika nilai $\mathrm{D}>\mathrm{D}_{\mathrm{N} ; \alpha}$ maka Ho ditolak, artinya data residual tidak menyebar normal. $\mathrm{D}_{\mathrm{N} ; \alpha}$ adalah nilai kritis berdasarkan tabel Kolmogorov-Smirnov dengan ukuran sampel $\mathrm{N}$ dan diuji pada taraf nyata $\alpha$. 


\section{b. Asumsi Homogenitas}

Menurut Montgomery (2009), pengujian kehomogenan ragam dapat dilakukan dengan menggunakan Uji Bartlett. Misalnya terdapat a perlakuan, maka hipotesis yang dapat diambil adalah:

$\mathrm{H}_{0}: \sigma_{1}^{2}=\sigma_{2}^{2}=\cdots=\sigma_{a}^{2}$ (varian residual homogen)

$\mathrm{H}_{1}$ : Paling sedikit sepasang tidak sama (varian residual tidak homogen)

Prosedur pada uji Bartlett ini menggunakan pendekatan sebaran chi-square dengan derajat bebas a-1.

Statistik ujinya adalah:

$\chi_{h}^{2}=2,3026 \frac{q}{c}$, dengan

$\mathrm{q}=(N-a) \log _{10} S_{p}^{2}-\sum_{i=1}^{a}\left(n_{i}-1\right) \log _{10} S_{i}^{2}$

$\mathrm{S}_{\mathrm{p}}^{2}=\frac{\sum_{i=1}^{a}\left(n_{i}-1\right) S_{i}^{2}}{N-a}$

$\mathrm{c}=1+\frac{1}{3(a-1)}\left(\sum_{i=1}^{a} \frac{1}{\left(n_{i}-1\right)}-\frac{1}{N-a}\right)$

Keputusan:

Tolak $\mathrm{H}_{0}$ jika $\chi_{h}^{2} \geq \chi_{\alpha ;(a-1)}^{2}$, dengan $\chi_{\alpha ;(a-1)}^{2}$ adalah berdistribusi chi-square dengan peluang $\alpha$ dan derajat bebas a-1.

\subsection{Data Hilang untuk Rancangan Bujur Sangkar Youden}

Menurut Cochran dan Cox (1957), perhitungan untuk mengestimasi data yang hilang pada Rancangan Bujur Sangkar Youden adalah sebagai berikut:

$x=\frac{\lambda[b K+a B+(a-1) A-G]-b A^{\prime}-(b-1) B_{a}+B_{a}^{\prime}}{b(b-1)(b-2)}$

dimana:

$x=$ data yang hilang

$\lambda=$ banyaknya tiap pasang perlakuan yang muncul dalam setiap baris

$a$ = banyaknya perlakuan/baris dalam percobaan

$b$ = banyaknya kolom dalam percobaan

$B=$ total pengamatan pada baris dimana terdapat data hilang

$K=$ total pengamatan pada kolom dimana terdapat data hilang

$A=$ total pengamatan pada perlakuan dimana terdapat data hilang

$G=$ total seluruh pengamatan dengan satu data hilang

$A^{\prime}=$ total pengamatan pada semua perlakuan yang muncul pada baris yang terdapat data hilang

$B_{a}=$ total baris yang terdapat perlakuan data yang hilang

$B_{a}^{\prime}=$ total nilai $B_{a}$ untuk semua perlakuan yang lain yang muncul pada baris yang terdapat data hilang

Apabila terdapat dua data hilang maka langkah-langkahnya sebagai berikut:

1. Tentukan nilai awal untuk salah satu data yang hilang. Nilai yang paling umum digunakan untuk salah satu pengamatan yang hilang adalah rata-rata rataan menggunakan rumus (Sugandhi dan Sugiarto, 1994):

$x_{i j k}=\frac{\bar{y}_{i . .}+\bar{y}_{. j .}+\bar{y}_{. . k}}{3}$

dengan:

$x_{i j k}=$ nilai awal salah satu data yang hilang

$\bar{y}_{i . .}=$ rata-rata baris yang mengandung data hilang

$\bar{y}_{. j .}=$ rata-rata kolom yang mengandung data hilang

$\bar{y}_{. . k}=$ rata-rata perlakuan yang mengandung data hilang 
2. Masukkan nilai awal yang telah ditentukan dalam langkah 1 ke dalam tabel pengamatan dan dugalah data hilang kedua dengan menggunakan persamaan (9).

3. Masukkan hasil estimasi pada langkah 2 ke dalam tabel pengamatan, kemudian nilai awal yang diperoleh dengan persamaan (10) diperbaiki menggunakan persamaan (9).

4. Langkah 2 dan 3 diulang-ulang sampai nilai estimasi data pertama konvergen dan data kedua juga konvergen.

5. Gunakan hasil estimasi kedua data hilang dari siklus iterasi yang terakhir bersama seluruh nilai pengamatan untuk dilakukan perhitungan pada analisis variansi dengan konsekuensi derajat bebas total dan derajat bebas galat berkurang 2 .

\subsubsection{Analisis Variansi untuk RBSY dengan Data Hilang}

Analisis variansi dalam rancangan bujur sangkar Youden dengan data hilang dihitung seperti pada data lengkap, hanya saja derajat bebas total dan derajat bebas galat dikurangi 2 . Dengan adanya data hilang, jumlah kuadrat perlakuan lebih tinggi dari yang seharusnya,

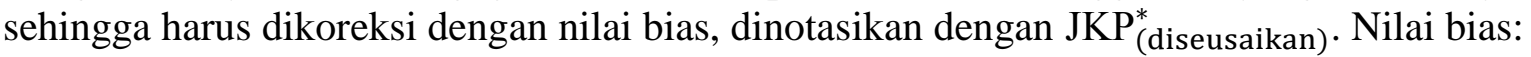

- Untuk satu data hilang

$$
\text { Bias }=\frac{\left(a B_{x}+b K_{x}-G_{x}-a b x\right)^{2}}{a b(a-1)(b-1)}
$$

- Untuk dua data hilang

$$
\text { Bias }=\frac{\left(a B_{x}+b K_{x}-G_{x y}-a b x\right)^{2}+\left(a B_{y}+b K_{y}-G_{x y}-a b y\right)^{2}}{a b(a-1)(b-1)}
$$

dimana $x$ dan $y$ adalah estimasi data hilang, $B_{x}$ dan $B_{y}$ yaitu total baris termasuk nilai estimasi, $K_{x}$ dan $K_{y}$ yaitu total kolom termasuk nilai estimasi dan $G_{x y}$ yaitu total seluruh

\begin{tabular}{|c|c|c|c|c|c|}
\hline $\begin{array}{l}\text { Sumber } \\
\text { Variansi }\end{array}$ & Derajat Bebas & Jumlah Kuadrat & Kuadrat Tengah & $F_{\text {hitung }}$ & $\mathrm{F}_{\text {tabel }}$ \\
\hline $\begin{array}{c}\text { Perlakuan } \\
\text { (disesuaikan) }\end{array}$ & $a-1$ & $\mathrm{JKP}_{\text {(diseusaikan) }}^{*}$ & $\mathrm{KTP}_{(\text {diseusaikan) }}^{*}$ & $\frac{\mathrm{KTP}_{\text {(diseusaikan) }}^{*}}{\mathrm{KTG}}$ & $\mathrm{F}_{(a-1) ;(a-1)(b-2)-2}(\alpha)$ \\
\hline Baris & $a-1$ & $\mathrm{JKB}$ & KTB & & \\
\hline Kolom & $b-1$ & JKK & KTK & & \\
\hline Galat & $\begin{array}{c}(a-1)(b-2) \\
-2\end{array}$ & JKG & KTG & & \\
\hline Total & $a b-1-2$ & JKT & & & \\
\hline
\end{tabular}
pengamatan termasuk nilai estimasi.

\subsubsection{Uji Lanjut untuk RBSY dengan Data Hilang}

Dalam uji LSD, langkah-langkah pengujiannya sebagai berikut:

1. Mengurutkan rata-rata perlakuan dari yang terkecil sampai yang terbesar.

2. Menghitung standar error dari perlakuan A dan perlakuan B yang telah disesuaikan:

- Untuk perlakuan tanpa ada data hilang

$$
S_{\bar{y}_{A .}-\bar{y}_{B .}}=\sqrt{\frac{2(\mathrm{KTG})}{b} \frac{b(a-1)}{a(b-1)}}
$$

- Untuk perlakuan yang memuat data hilang

$$
S_{\bar{y}_{A .}-\bar{y}_{B .}}=\sqrt{\operatorname{KTG} \frac{b(a-1)}{a(b-1)}\left(\frac{1}{b_{A}}+\frac{1}{b_{B}}\right)}
$$

dengan $b_{A}$ dan $b_{B}$ disebut ulangan efektif, yang merupakan penjumlahan dari nilai yang diamati di setiap kolomnya. Misalkan mencari nilai-nilai pada $b_{A}$ : 


\begin{tabular}{ccl}
\hline Nilai & Perlakuan A & \multicolumn{2}{c}{ Perlakuan B } \\
\hline 1 & Muncul & $\begin{array}{l}\text { Muncul pada baris yang bersesuaian dengan perlakuan A } \\
\text { dan muncul pada kolom yang bersesuaian dengan } \\
\text { perlakuan A }\end{array}$ \\
\hline$\frac{2}{3}$ & Muncul & $\begin{array}{l}\text { Muncul pada salah satu kejadian (baris/kolom) yang } \\
\text { bersesuaian dengan perlakuan A }\end{array}$ \\
\hline$\frac{1}{3}$ & Muncul & $\begin{array}{l}\text { Tidak muncul pada baris maupun kolom yang bersesuaian } \\
\text { dengan perlakuan A }\end{array}$ \\
\hline 0 & Tidak muncul & \\
\hline
\end{tabular}

Cara yang sama digunakan untuk mencari nilai-nilai pada $b_{B}$.

3. Menghitung LSD

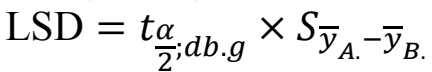

dimana $\frac{t_{\frac{\alpha}{2}}}{d b . g}$ merupakan nilai pada tabel distribusi t dengan tingkat signifikansi $\alpha$ dan derajat bebas galat (db.g).

4. Jika $\left|\bar{y}_{A .}-\bar{y}_{B .}\right|>$ LSD maka pasangan perlakuan tersebut berbeda signifikan.

\section{METODE PENELITIAN}

\subsection{Data}

Data yang digunakan pada penelitian ini adalah data sekunder yang diperoleh dari buku Gaspersz (1991) berupa Rancangan Bujur Sangkar Youden yang dimodifikasi sehingga terdapat 2 data hilang yang terdiri dari 5 baris, 4 kolom dan 5 perlakuan.

\subsection{Metode Analisis Data}

Langkah dalam analisis data penelitian ini adalah:

1. Melakukan input data

2. Memodelkan dengan model linier Rancangan Bujur Sangkar Youden

3. Melakukan estimasi data yang hilang

4. Melakukan ANOVA

5. Pengujian asumsi normalitas dan homogenitas

6. Uji lanjut

7. Penarikan kesimpulan

\section{HASIL DAN PEMBAHASAN}

\subsection{Model Linier}

Suatu penelitian dilakukan untuk mengetahui pengaruh 5 metode perakitan terhadap lamanya waktu perakitan komponen X (dalam satuan detik). Rancangan yang digunakan yaitu Rancangan Bujur Sangkar Youden (RBSY). Penelitian ini dilakukan oleh 4 operator dan dijalankan selama 5 hari. Model linier yang digunakan adalah:

$$
\begin{gathered}
y_{i j k}=\mu+\alpha_{i}+\beta_{j}+\tau_{k}+\varepsilon_{i j k} \\
i=1,2, \ldots, 5 \\
j=1,2, \ldots, 4 \\
k=1,2, \ldots, 5
\end{gathered}
$$

\subsection{Estimasi Data Hilang}

Dalam tulisan ini terdapat dua buah data hilang pada RBSY, yaitu data pada baris kelima, kolom ketiga dan perlakuan A $\left(x_{531}\right)$ dan data pada baris keempat, kolom keempat dan perlakuan E $\left(x_{445}\right)$. Data tersebut dapat dilihat pada tabel berikut: 


\begin{tabular}{|c|c|c|c|c|c|}
\hline \multirow{2}{*}{ Hari (Baris) } & \multicolumn{4}{|c|}{ Operator (Kolom) } & \multirow{2}{*}{$\begin{array}{c}\text { Jumlah respon tiap } \\
\text { baris }\left(y_{i . .}\right)\end{array}$} \\
\hline & 1 & 2 & 3 & 4 & \\
\hline 1 & $B=627$ & $A=337$ & $E=195$ & $\mathrm{C}=278$ & 1437 \\
\hline 2 & $C=251$ & $\mathrm{D}=248$ & $\mathrm{~B}=520$ & $A=396$ & 1415 \\
\hline 3 & $E=185$ & $B=602$ & $\mathrm{C}=240$ & $\mathrm{D}=196$ & 1223 \\
\hline 4 & $A=344$ & $\mathrm{C}=233$ & $\mathrm{D}=211$ & $E=\ldots$ & 788 \\
\hline 5 & $\mathrm{D}=273$ & $E=199$ & $A=\ldots$ & $\mathrm{B}=537$ & 1009 \\
\hline $\begin{array}{c}\text { Jumlah respon tiap } \\
\text { kolom }\left(y_{. j .}\right)\end{array}$ & 1680 & 1619 & 1166 & 1407 & 5872 \\
\hline
\end{tabular}

Data yang hilang diestimasi dengan cara iterasi, sehingga diperoleh hasil estimasi untuk $x_{531}$ sebesar 332,6875 dan $x_{445}$ sebesar 163,4375 .

\subsection{Analisis Variansi}

Nilai estimasi untuk data hilang tersebut bersama seluruh nilai pengamatan digunakan untuk menyusun analisis variansi. Tabel analisis variansinya disusun sebagai berikut:

$\begin{array}{cccccc}\text { Sumber Variansi } & \begin{array}{c}\text { Derajat } \\ \text { Bebas }\end{array} & \begin{array}{c}\text { Jumlah } \\ \text { Kuadrat }\end{array} & \begin{array}{c}\text { Kuadrat } \\ \text { Tengah }\end{array} & F_{\text {hitung }}\end{array} \quad$ F tabel

\begin{tabular}{cccccc}
\hline $\begin{array}{c}\text { Perlakuan } \\
\text { (disesuaikan) }\end{array}$ & 4 & 334615,76611 & 83653,94153 & 27,58493 & 4,53368 \\
\hline Baris & 4 & 39419,61523 & 9854,90381 & \\
\hline Kolom & 3 & 3529,03203 & 1176,34401 & \\
\hline Galat & 6 & 18195,5749 & 3032,59582 & \\
\hline Total & 17 & 395759,98828 & & \\
\hline
\end{tabular}

Pada tabel analisis variansi diatas nilai $\mathrm{F}_{\text {hitung }}>\mathrm{F}_{\text {tabel }}$ sehingga dapat disimpulkan bahwa terdapat pengaruh metode perakitan terhadap lamanya waktu perakitan komponen $\mathrm{X}$.

\subsection{Uji Asumsi}

\section{a. Asumsi Normalitas}

Hipotesis:

$\mathrm{H}_{0}$ : data residual menyebar normal

$\mathrm{H}_{1}$ : data residual tidak menyebar normal

Taraf Signifikansi: $\alpha=5 \%$

Statistik Uji: $\mathrm{D}=\sup \left|\mathrm{S}(\mathrm{x})-\mathrm{F}_{0}(\mathrm{x})\right|=0,1$

Kriteria Uji: $\mathrm{H}_{0}$ ditolak apabila $\mathrm{D}>\mathrm{D}_{\mathrm{N} ; \alpha}$

Keputusan:

Berdasarkan hasil uji Kolmogorov-Smirnov diperoleh nilai $\mathrm{D}=0,1$. Nilai tersebut lebih kecil daripada nilai kritis pada tabel Kolmogorov-Smirnov dengan $\alpha=5 \%$ dan $\mathrm{N}=$ 20 yaitu 0,294, sehingga dapat disimpulkan bahwa data residual berdistribusi normal.

\section{b. Asumsi Homogenitas}

Hipotesis:

$\mathrm{H}_{0}: \sigma_{1}^{2}=\sigma_{2}^{2}=\cdots=\sigma_{5}^{2}$ (varian residual homogen)

$\mathrm{H}_{1}$ : Paling sedikit sepasang tidak sama (varian residual tidak homogen)

Taraf Signifikansi: $\alpha=5 \%$

Statistik Uji: $\chi_{h}^{2}=2,3026 \frac{q}{c}=4,97$ 
Kriteria Uji: $\mathrm{H}_{0}$ ditolak apabila $\chi_{h}^{2} \geq \chi_{\alpha ;(a-1)}^{2}$

Keputusan:

Berdasarkan uji Bartlett diperoleh nilai $\chi_{h}^{2}=4,97$. Nilai tersebut lebih kecil daripada nilai kritis pada tabel chi-square dengan $\alpha=5 \%$ dan derajat bebas 4 yaitu 9,49, sehingga dapat disimpulkan bahwa varian data residual homogen.

\subsection{Uji Lanjut}

Dikarenakan metode perakitan memiliki pengaruh terhadap lamanya waktu perakitan komponen X, maka akan dilakukan uji lanjut. Uji lanjut yang digunakan dalam tulisan ini adalah uji LSD (Least Significant Difference). Pengujian dilakukan terhadap perlakuan yang disesuaikan. Rata-rata perlakuan yang telah disesuaikan diurutkan dari terkecil hingga terbesar. Selanjutnya dihitung standar error dan nilai LSD untuk masing-masing pasangan perlakuan yang diamati.

\begin{tabular}{ccccccc}
\hline No & Perlakuan $i$ dan $j$ & $b_{i}$ & $b_{j}$ & $S_{\bar{y}_{i}-\bar{y}_{j}}$ & LSD & Kesimpulan \\
\hline 1 & A dan B & 2,66667 & 3 & 47,86747 & 117,12748 & Berbeda \\
\hline 2 & A dan C & 3 & 3,33333 & 45,26242 & 110,75316 & Tidak Berbeda \\
\hline 3 & A dan D & 2,33333 & 3 & 49,64459 & 121,47595 & Tidak Berbeda \\
\hline 4 & A dan E & 2 & 2 & 56,87503 & 139,16818 & Berbeda \\
\hline 5 & B dan C & 4 & 4 & 40,21672 & 98,40676 & Berbeda \\
\hline 6 & B dan D & 4 & 4 & 40,21672 & 98,40676 & Berbeda \\
\hline 7 & B dan E & 3,33333 & 3 & 45,26242 & 110,75316 & Berbeda \\
\hline 8 & C dan D & 4 & 4 & 40,21672 & 98,40676 & Tidak Berbeda \\
\hline 9 & C dan E & 3 & 2,66667 & 47,86747 & 117,12748 & Tidak Berbeda \\
\hline 10 & D dan E & 3 & 2,66667 & 47,86747 & 117,12748 & Tidak Berbeda \\
\hline
\end{tabular}

Hasil dari uji LSD dapat dilihat sebagai berikut:

$\begin{array}{ccccc}\bar{y}_{E} & \bar{y}_{D} & \bar{y}_{C} & \bar{y}_{A} & \bar{y}_{B} \\ 186,18125 & 237,13125 & 250,51042 & 351,31458 & 566,89375\end{array}$

Garis bawah berarti tidak berbeda signifikan

Dari hasil uji LSD di atas dapat dilihat bahwa metode perakitan A, C, dan D memiliki pengaruh yang sama secara statistik. Begitu pula metode perakitan D dan E juga memiliki pengaruh yang sama secara statistik. Apabila hasil tersebut akan diaplikasikan, maka metode perakitan yang disarankan yaitu metode perakitan E karena mempunyai rata-rata waktu perakitan yang paling cepat, tetapi secara statistik tidak berbeda dengan metode perakitan D.

\section{KESIMPULAN}

Berdasarkan hasil dan pembahasan yang diperoleh pada bab sebelumnya, dapat disimpulkan bahwa data hilang yang terdapat dalam Rancangan Bujur Sangkar Youden (RBSY) harus diestimasi terlebih dahulu untuk menyusun analisis variansi dan uji lanjutnya. Perhitungan nilai yang diestimasi dapat dilakukan secara manual maupun digunakan komputasi pada software R. Analisis variansi pada RBSY yang terdapat dua data hilang dilakukan dengan mengoreksi nilai jumlah kuadrat perlakuan dengan nilai biasnya. Selain itu, derajat bebas total dan derajat bebas galat akan berkurang dua (banyaknya data hilang). Uji lanjut pada RBSY dengan dua data hilang digunakan untuk membandingkan pengaruh dari setiap perlakuan dengan menghitung standar error dan nilai LSD. Nilai standar error berbeda untuk masing-masing pasangan perlakuan yang diamati. Hal tersebut 
mengakibatkan nilai LSD juga akan berbeda untuk masing-masing pasangan perlakuan yang diamati.

\section{DAFTAR PUSTAKA}

Cochran, W. G. \& Cox, G. M. 1957. Experimental Designs $2^{\text {nd }}$ edition. New York: John Wiley \& Sons.

Daniel, W. W. 1989. Statistika Nonparametrik Terapan. Diterjemahkan oleh: Alex Tri Jantjono W. Jakarta: Gramedia. Terjemahan dari: Applied Nonparametric Statistics.

Gaspersz, V. 1991. Teknik Analisis dalam Penelitian Percobaan 1. Bandung: Tarsito.

Kusriningrum, R. S. 2008. Perancangan Percobaan. Surabaya: Airlangga University Press.

Montgomery, D. C. 2009. Design and Analysis of Experiment $7^{\text {th }}$ edition. New York: John Wiley \& Sons.

Oehlert, G. W. 2010. A First Course in Design Analysis of Experiments. University of Minnesota.

Sugandhi, E. \& Sugiarto. 1994. Rancangan Percobaan. Yogyakarta: Andi Offset.

Suwanda. 2011. Desain Eksperimen untuk Penelitian Ilmiah. Bandung: Alfabeta. 